\title{
,CONTEXTUALIZAÇÃO E EXPERIMENTAÇÃO UMA ANÁLISE DOS ARTIGOS PUBLICADOS NA SEÇÃO “EXPERIMENTAÇÃO NO ENSINO DE QUÍMICA” DA REVISTA QUÍMICA NOVA NA ESCOLA 2000-2008
}

\author{
CONTEXTUALIZATION AND EXPERIMENTATION \\ AN ANALYSES OF PAPERS PUBLISHED ON THE SECTION \\ "EXPERIMENTATION ON CHEMISTRY EDUCATION" FROM THE \\ JOURNAL "QUIMICA NOVA NA ESCOLA" 2000-2008
}

\author{
Raquel Thomaz da Silva* \\ Ana Cristina Trindade Cursino* \\ Joanez Aparecida Aires*** \\ Orliney Maciel Guimarães ${ }^{* * *}$
}

\section{Resumo}

Este estudo investigou artigos publicados na seção "Experimentação no Ensino de química” da Revista Química Nova na Escola entre 2000 e 2008. O objetivo foi analisar se e como a contextualização vem sendo usada nos experimentos incluídos nessa seção. A fundamentação teórica consistiu no estudo dos conceitos de experimentação e contextualização. A metodologia incluiu a seleção e análise de experimentos verificando: qual concepção de contextualização estava sendo usada; a coerência entre a contextualização e os conceitos químicos envolvidos; quais conteúdos foram mais recorrentes e se ao longo desse período houve mudança na freqüência e na concepção de contextualização proposta nos experimentos. Os resultados indicaram que a concepção de contextualização mais recorrente foi a de "exemplificação de fatos do cotidiano".

Palavras-chave: Contextualização, Experimentação, Ensino de Química.

\begin{abstract}
\footnotetext{
* Graduanda do Curso de Química da Universidade Federal do Paraná

** Graduanda do Curso de Química da Universidade Federal do Paraná

*** Professora Doutora do Curso de Química da Universidade Federal do Paraná

${ }^{* * * *}$ Professora Doutora do Curso de Química da Universidade Federal do

Paraná
}

This study investigated papers published in the section "Experimentation in the Chemistry Education”, of the New Chemistry at School Journal, from 2000 to 2008. The aim was to examine if and how contextualization has been used in the experiments included in that journal section. The theoretic background was grounded on the concept studies of experimentation and contextualization. Methodology included selection and analysis of experiments, finding out: which contextualization concept was used; check the coherence between contextualization and chemistry concepts involved; identify which 


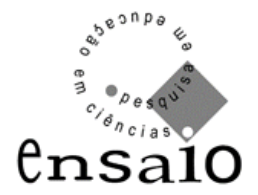

subjects were more frequently selected, as well as, analyse if along the period studied there was any change on the frequence and conception of experiments proposed. Results indicated that the most common contextualization concept was "the use of daily facts exemplification”.

Key-words: Contextualization, Experimentation, Chemistry Teaching.

A importância do ensino de Química na Educação Básica vem sendo justificada pela necessidade da formação do cidadão para que este possa participar da sociedade atual com maior compreensão e criticidade. Santos e Schnetzler (1996) consideram que a função do ensino de Química é desenvolver a capacidade de tomada de decisão, o que implica a necessidade de vinculação do conteúdo trabalhado com o contexto social em que o aluno está inserido. Esses autores afirmam que:

\footnotetext{
O objetivo básico do ensino de química para formar o cidadão compreende a abordagem de informações químicas fundamentais que permitam ao aluno participar ativamente na sociedade tomando decisões com consciência de suas conseqüências. Isso implica que o conhecimento químico aparece não com um fim em si mesmo, mas com objetivo maior de desenvolver as habilidades básicas que caracterizam o cidadão: participação e julgamento (SANTOS \& SCHNETZLER, 1996, p.29).
}

O ensino de química também tem a função de apresentar ao aluno um conceito de Ciência como atividade humana em construção, que leva em conta o papel social da Ciência. Em concordância com essa visão, se faz necessário recorrer a metodologias que contribuam para uma aprendizagem de Química que colabore para a concretização desses objetivos. Uma dessas opções metodológicas que pode trazer essa contribuição é a Experimentação.

Entendemos que quando a experimentação é desenvolvida juntamente com a contextualização, ou seja, levando em conta aspectos sócio-culturais e econômicos da vida do aluno, os resultados da aprendizagem poderão ser mais efetivos. A partir dessa compreensão, o objetivo neste estudo foi analisar se e como a contextualização vem sendo incorporada aos experimentos presentes nos artigos publicados na seção 


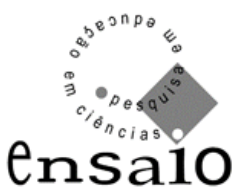

“Experimentação no Ensino de Química”, na Revista Química Nova na Escola, no período de 2000 a 2008.

\section{RELAÇÕES ENTRE EXPERIMENTAÇÃO E CONTEXTUALIZAÇÃO}

O caráter particular da experiência e sua natureza factual, já eram reconhecidos há mais de 2300 anos. Aristóteles já dizia que “quem possua a noção sem a experiência e conheça o universal ignorando o particular nele contido, enganar-se-á muitas vezes no tratamento” (apud GIORDAN, 1999, p.43).

A partir do século XVII, foram dados os primeiros passos para a Ciência Moderna, onde a experimentação passou a desempenhar importante papel no desenvolvimento de uma metodologia científica que rompia com os padrões anteriores de que o homem e a natureza tinham relação com o divino, passando a se basear na racionalização, indução e dedução. O modelo de formulação de enunciados, partindo de regularidades de resultados entre os experimentos, caracteriza o conceito indutivista proposto por Francis Bacon. Ainda no século XVII, Galileu também atribui à experimentação "um papel central no fazer ciência, o de legitimadora” (GIORDAN, 1999, p.44). Essa compreensão de Ciência se mantém e é fortalecida no início do século $\mathrm{XX}$, com a concepção positivista elaborada por Comte.

No que se refere ao papel da experimentação no processo ensino-aprendizagem de ciências, Galiazzi et al. (2001) afirmam que há mais de um século as atividades experimentais foram implantadas nas escolas, fortemente influenciadas pelos trabalhos desenvolvidos nas universidades. Segundo estes autores, o objetivo era melhorar a aprendizagem do conteúdo científico, porque os alunos aprendiam os conteúdos, mas não sabiam aplicá-los. Mas é na década de 60 do século XX, que a aposta na experimentação como proposta de melhoria do ensino de ciências atingiu seu auge, essencialmente por influência dos Projetos Curriculares Americanos, tais como o CHEMS (Chemical Educational Material Study) e CBA (Chemical Bond Approach Project). 


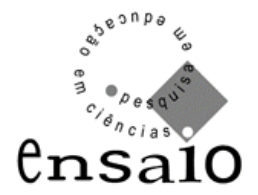

Estes projetos chegaram também ao Brasil e foram elaborados sob a justificativa do crescente desenvolvimento da Ciência e Tecnologia, o qual teria levado à necessidade de reformulação do ensino de ciências. Todavia, sem entrar nos detalhes dos problemas relacionados àqueles projetos, sabe-se que a concepção de ciência presente nas propostas de experimentação, oriundas ou não daqueles projetos, correspondia à concepção empírico-positivista, a qual muito tem sido criticada pelos pesquisadores da área de ensino de ciências atuais.

Por outro lado, apesar das críticas, pesquisas (GIORDAN, 1999) têm ressaltado a importância da experimentação para o processo ensino-aprendizagem de ciências/química. Mesmo assim, Galiazzi et al. (2001) argumentam que embora muitos professores acreditem que possam transformar o ensino de Ciências através da experimentação, as atividades experimentais são pouco freqüentes nas escolas, sob a justificativa da inexistência de laboratórios, e aquelas que os possuem, não têm recursos para mantê-los.

Essa problemática da pouca freqüência da experimentação nas aulas de ciências/química, embasada na falta de recursos, é bastante recorrente, porém não se sustenta, uma vez que revistas direcionadas para a educação em ciências contêm, frequentemente, experimentos com materiais de baixo custo sobre temas abrangentes que contemplam diversos conteúdos. Sendo assim, inferimos que a pouca freqüência das aulas experimentais pode ser resultado de uma problemática ainda mais complexa, a qual corresponde à formação dos professores, visto que os cursos de graduação em ciências, de modo geral e, em química, em particular, têm historicamente priorizado a formação do bacharel, em detrimento da formação do professor.

Em conseqüência disso, egressos dos cursos de licenciatura, acabam tendo uma formação pedagógica “ambiental”, a qual, conforme Maldaner (2000), é aquela "adquirida" por meio da reprodução das ações dos professores com os quais tiveram contato ao longo da sua vida escolar e acadêmica. Ou seja, têm uma formação pouco refletida e fracamente fundamentada, e acabam difundindo aquela concepção de experimentação empírico-positivista, que tanto vem sendo criticada pelos pesquisadores da área de ensino de ciências. 


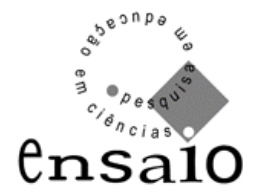

Em outras palavras, como argumentam Galiazzi e Gonçalves (2004), o que acaba acontecendo é que a concepção de ciência dos egressos que tiveram essa formação, normalmente é aquela que corrobora a visão empírico-positivista de ciência. Nesta, a função da experimentação é comprovar a teoria, por meio de uma abordagem tradicional “do demonstrar para crer”, contribuindo para manter a hegemonia de uma Ciência tida como objetiva, neutra e apoiada em teorias originadas apenas da observação.

É necessário, portanto, superar essa compreensão de que a atividade experimental tem a função única e exclusiva de comprovação da teoria, uma vez que a estruturação do conhecimento científico depende de uma abordagem experimental, porque é na ocorrência da investigação que acontece a organização desse conhecimento. A experimentação é uma parte imprescindível do processo de investigação. Essa necessidade é reconhecida entre aqueles que fazem o ensino de ciências. Sendo assim, a importância da inclusão da experimentação, está na caracterização de seu papel investigativo e de sua função pedagógica em auxiliar o aluno na compreensão dos fenômenos químicos (SANTOS \& SCHNETZLER, 1996).

As atividades experimentais devem ser encaradas como um dos instrumentos do discurso das Ciências, e como tal, devem ser incluídas no ambiente de sala de aula, a fim de permitir a "enculturação" de alunos e professores. Devem permitir que os alunos possam aprender não só as teorias das Ciências, entre elas a Química, mas também como se constrói o conhecimento científico em um processo de questionamento, discussão de argumentos e validação desses argumentos por meio do diálogo oral e escrito, com uma comunidade argumentativa que começa na sala de aula, mas a transcende.

No que se refere ao potencial da experimentação como metodologia de ensino, Giordan (1999) considera ser consenso que a experimentação desperta interesse entre os alunos, independente do nível de escolarização, uma vez que esta tem caráter motivador, lúdico, vinculado aos sentidos. Em decorrência disso, a experimentação pode aumentar a capacidade de aprendizado.

Lima et al. (2007) dizem que os experimentos demonstrativos ajudam a focar a atenção do estudante nos comportamentos e propriedades de substâncias químicas. 


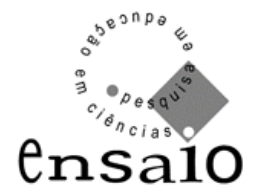

Portanto, a implementação e interpretação de experimentos contribuem para a construção de conceitos químicos por parte dos alunos.

Na perspectiva da discussão das potencialidades da experimentação como forma de melhorar o processo ensino-aprendizagem, bem como contribuir para um ensino de química contextualizado, Chassot et al. (1993) apresentam algumas reflexões. No que se refere à experimentação, estes autores defendem o "desenvolvimento de uma Química que tenha na experimentação uma forma de aquisição de dados da realidade, utilizados para a reflexão crítica do mundo e para o aprimoramento do desenvolvimento cognitivo" (CHASSOT et al., 1993, p.48). No que se refere à contextualização, defendem o emprego do ensino de Química como meio de educação para a vida, determinando relações entre os conteúdos aprendidos e o dia-a-dia dos alunos, bem como com outras áreas do conhecimento, levando o aluno-cidadão a refletir, compreender, discutir e agir sobre seu mundo.

É nessa perspectiva, de um ensino de química para a vida, que acreditamos que quando a experimentação é desenvolvida ponderando fatores da contextualização, favorecendo a inter-relação entre diferentes conhecimentos para a construção de significados novos, o resultado pode ser mais efetivo. No entanto, ter clara qual concepção de contextualização que estamos adotando é fundamental para que novas metodologias de ensino possam ser desenvolvidas com foco na formação para o exercício da cidadania.

A contextualização, juntamente com a interdisciplinaridade, corresponde a um dos princípios citados pelos PCNEM (Parâmetros Curriculares Nacionais para o Ensino Médio) para promover uma aprendizagem focada na formação do cidadão. No entanto, autores argumentam (GOUVEA \& MACHADO, 2005; RICARDO, 2005) que nos termos em que a contextualização foi descrita nos Parâmetros Curriculares Nacionais, esta fica restrita a situações do universo do aluno de forma bastante vaga, por isso a necessidade de busca por uma melhor compreensão do seu significado.

Possivelmente, essa possa ter sido a razão para que, em 2002, tenha sido elaborado os PCN+ (BRASIL, 2002) como forma de complementar a proposta anterior. Neste documento encontra-se que a contextualização deve dar "significado aos conteúdos" e 
ensaio

facilitar o "estabelecimento de ligações com outros campos do conhecimento" (BRASIL, 2002, p.87). Gouvêa e Machado (2005) comentam que nos documentos do PCN+ (BRASIL, 2002) o objetivo da contextualização do ensino não é promover uma ligação artificial entre o que é ensinado e a vida diária do aluno. Não é apenas exemplificar um conteúdo, mas que é propor "situações problemáticas reais e buscar o conhecimento necessário para entendê-las e procurar solucioná-las” (GOUVÊA \& MACHADO, 2005, p.17).

Desse ponto de vista, a contextualização inter-relaciona conhecimentos diferentes contribuindo para a estruturação de novos significados. Contextualizar, portanto, é construir significados. Wartha e Alário (2005) argumentam que esses significados incorporam valores, porque explicitam o cotidiano, constroem a compreensão de problemas do entorno social e cultural e facilitam viver o processo da descoberta.

De acordo com Gouvea e Machado (2005), o texto da Lei de Diretrizes e Bases de 1996, já pontuava que quando se considera o contexto de vivência do aluno, explicitam-se concepções que muitas vezes podem ser diferentes daquelas que a ciência propõe para explicar a realidade. No entanto, os mesmos autores argumentam que atualmente, um dos principais problemas no ensino de Química ainda é a distância entre o conteúdo ensinado na escola, e a realidade vivenciada pelos alunos. Nota-se que estes têm dificuldades em selecionar informações científicas de fontes diversas e relacioná-las com seu dia-a-dia, questionando e concluindo sobre estas informações.

Liso et al. (2002) destacam a importância de acrescentar realidade nos currículos de química utilizando a química cotidiana para estabelecer relações entre o conhecimento cotidiano do aluno e o conhecimento científico. Citando Solsona, Liso et al. (2002) defendem a relevância da interação entre o aluno e o meio em que está inserido, objetivando capacitar os indivíduos para que entendam melhor o mundo onde vivem, produzindo também motivação suficiente para que busquem a razão dos fenômenos que os rodeiam. Cortizo (apud LISO et al., 2002) menciona que deve haver uma conexão efetiva e real da escola com as vivências, sentimentos e necessidades dos estudantes, buscando um equilíbrio harmônico entre o que aprendem em aula e suas vidas cotidianas. O emprego da vida cotidiana como conceito central para a aprendizagem de conteúdos 


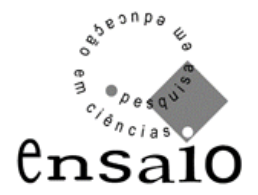

científicos traz implícita uma concepção do ensino de ciências que surge, entre outros fatores, da necessidade de despertar o interesse pela ciência nos alunos desmotivados que se encontram nas salas de aula, devido à obrigatoriedade do ensino de matérias científicas.

As relações entre conhecimento científico, conhecimento cotidiano e atividades de ensino vêm sendo objeto de interesse de educadores no decorrer da história. Nesse sentido, Lopes (1998) argumenta que já nos trabalhos de Dewey, ainda que seus trabalhos não tivessem por objetivo colocar em questão a problemática do cotidiano, encontram-se preocupações com uma escola que não fosse a formação "para a vida", mas que se constituísse "na própria vida” produtiva real.

Apesar dos intentos por um ensino de ciências que subsidie o cidadão para atuar e se posicionar criticamente na sociedade, em relação a assuntos que envolvem conhecimentos científicos, não se constitua exatamente em uma novidade, esse objetivo ainda não foi concretizado. Para isso, se faz necessário que o ensino de Ciências/Química conceda importância ao contexto a cerca dos alunos, tendo como base fenômenos que alcançam popularidade através dos meios de comunicação e outros, não tão populares, mas que são encontrados nos cenários em que o aluno está inserido. Esses fenômenos não devem servir apenas para introduzir ou motivar, mas também para propor situações problemáticas que possam ser aplicadas a vida diária (LISO et al., 2002).

Liso et al. (2002) também ressaltam que não é suficiente usar a Química cotidiana apenas como exercício de aplicação da teoria ou como introdução aos conteúdos científicos. Defendem que seria mais importante que os conteúdos surgissem das atividades diárias em vez de partir dos conteúdos e exemplificar com atividades vividas diariamente (LISO et al., 2002).

Todavia, se faz necessário ressaltar que existem diferenças entre a "contextualização no ensino" e o "ensino de Ciências relacionado ao cotidiano". Para Santos e Mortimer, "enquanto a contextualização no ensino aborda o ensino de Ciências no seu contexto social com as inter-relações econômicas, sociais, culturais, etc., o ensino de Ciências do cotidiano trata dos conceitos científicos relacionadas aos fenômenos do cotidiano" (apud WARTHA \& ALÁRIO, 2005, p.43). O problema do último caso é que a 


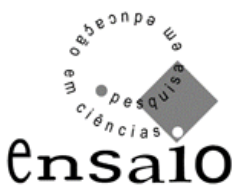

abordagem continua centrada apenas nos conceitos, reproduzindo aquele ensino de ciências memorístico, com um fim em si mesmo, o qual vem sendo criticado.

Para Wartha e Alário (2005) contextualizar é considerar a vivência e as experiências obtidas, se apropriando também de novos conhecimentos. É elaborar conhecimento no contexto da sociedade em que se vive e na estrutura mundial atual. Isso ajuda o aluno a compreender a importância de fenômenos e fatos que ocorrem diariamente a sua volta.

Para Chassot et al. (1993), a Química contextualizada é aquela politizada, que proporciona ao aluno a realização de atividades que lhe permita ponderar sobre o conhecimento existente. Assim, necessita criar condições para que este conhecimento possa ser aplicado às suas ações, desenvolvendo capacidade de entender o mundo e dessa forma, poder modificá-lo.

Estes autores argumentam ainda que uma Química Contextualizada é aquela que é útil para o cidadão, podendo ser caracterizada pela aplicação do conhecimento químico para facilitar a compreensão de fenômenos químicos que estão presentes em diversas situações na vida diária. Em outras palavras, ensinar química de modo contextualizado é "abrir as janelas da sala de aula para o mundo, é promover relação entre o que se aprende e o que é preciso para a vida” (CHASSOT et al., 1993, pág.50).

\section{MÉTODOS E TÉCNICAS}

Foram pesquisados 44 artigos publicados na seção "Experimentação no Ensino de Química” da Revista Química Nova na Escola, nas edições publicadas nos anos de 2000 a 2008. Os artigos foram analisados a partir de 5 critérios, relacionados a seguir:

Critério 1: Selecionar na Revista Química Nova na Escola, na seção "Experimentação no Ensino de Química”, artigos contendo sugestão de experimentos para aplicação em turmas de Ensino Médio que contemplassem "alguma indicação de contextualização".

Critério 2: Analisar qual concepção de contextualização está presente nestes experimentos. (Quadro 1) 


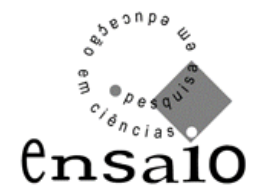

Critério 3: Verificar se a contextualização é coerente com os conceitos químicos envolvidos no experimento.

Critério 4: Verificar quais são os conteúdos contextualizados mais recorrentes.

Critério 5: Analisar se ao longo das edições de 2000 a 2008 houve aumento na proposição de artigos com experimentos contextualizados.

\section{RESULTADOS E DISCUSSÃO}

No Critério 1, tinha-se por objetivo fazer um levantamento dos artigos com sugestões de experimentação que contemplassem alguma indicação de contextualização, para que, a partir deste, fosse possível identificar quais concepções de contextualização estavam presentes nos artigos.

Este primeiro levantamento indicou que durante o período analisado foram publicados 44 artigos na seção “Experimentação no Ensino de Química”. Dentre estes, 30 artigos (68\%) contemplam alguma indicação de contextualização e, 14 (32\%) não contemplam.

No Critério 2, foi analisada a "concepção de contextualização" apresentada nos artigos (Quadro 1). Neste estudo foram consideradas as seguintes concepções de contextualização:

a) contextualização como exemplificação de fatos do cotidiano: esse tipo de contextualização apenas exemplifica pontualmente uma ocorrência de um fenômeno químico do cotidiano, não o desenvolvendo de modo a propiciar uma reflexão social, econômica e cultural mais ampla. Corresponde ao "ensino de ciências relacionado ao cotidiano”, segundo Mortimer e Santos (1999).

b) contextualização como estratégia de ensino aprendizagem: nesse tipo de contextualização identifica-se o emprego de situações do cotidiano como estratégia para tentar facilitar a compreensão de conceitos químicos por parte dos alunos, também sem desenvolver uma reflexão social, econômica e cultural.

c) contextualização como desenvolvimento de atitudes e valores para a formação do cidadão crítico: esse tipo de contextualização corresponde àquela que vem sendo 


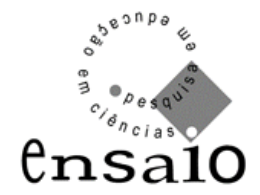

defendida nos documentos oficiais, especialmente nos PCN+, bem como na literatura da área de ensino de ciências, a qual deve formar o aluno/cidadão de modo a facilitar sua compreensão e melhorar sua capacidade de atuação na sociedade. Corresponde a “contextualização no ensino”, segundo Mortimer e Santos (1999).

Quadro 1 - Artigos que apresentam contextualização e sua respectiva concepção

\begin{tabular}{|c|c|c|}
\hline Data & Título & Tipo de Contextualização \\
\hline Maio/08 & Catalisando a Hidrólise da Uréia em Urina & $\begin{array}{l}\text { Exemplificação de fatos do } \\
\text { cotidiano }\end{array}$ \\
\hline Maio/08 & $\begin{array}{l}\text { Estudo da Atividade Proteolítica de } \\
\text { Enzimas Presentes em Frutos }\end{array}$ & $\begin{array}{l}\begin{array}{l}\text { Exemplificação de fatos } \\
\text { cotidiano }\end{array} \\
\end{array}$ \\
\hline Novembro/07 & $\begin{array}{l}\text { Corrosão de Metais por produtos de } \\
\text { limpeza }\end{array}$ & Estratégia de ensino aprendizagem \\
\hline Novembro/07 & \begin{tabular}{llrr} 
Protótipo & de & \multicolumn{2}{c}{ Reator Anaeróbio: } \\
Tratamento de & Esgoto Doméstico nas \\
Escolas & & & \\
\end{tabular} & $\begin{array}{l}\text { Desenvolvimento de atitudes e } \\
\text { valores para a formação de um } \\
\text { cidadão crítico }\end{array}$ \\
\hline Novembro/07 & $\begin{array}{l}\text { Experimentos para a Identificação de Íons } \\
\text { Ferro em Medicamentos Comerciais }\end{array}$ & $\begin{array}{l}\begin{array}{l}\text { Exemplificação de fatos } \\
\text { cotidiano }\end{array} \\
\end{array}$ \\
\hline Nove & $\begin{array}{l}\text { Um experimento Simples e de Baixo } \\
\text { Custo para Compreender a Osmose }\end{array}$ & $\begin{array}{l}\text { Desenvolvimento de atitudes e } \\
\text { valores para a formação de um } \\
\text { cidadão crítico }\end{array}$ \\
\hline Maio/07 & $\begin{array}{l}\text { Investigando Componentes Presentes no } \\
\text { Leite em uma Atividade Interativa }\end{array}$ & Estratégia de ensino aprendizagem \\
\hline Maio/07 & 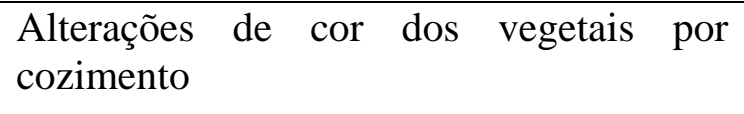 & $\begin{array}{l}\text { Exemplificação de fatos } \\
\text { cotidiano }\end{array}$ \\
\hline $\mathrm{ro} / 06$ & $\begin{array}{l}\text { Equilíbrio químico de sais pouco solúveis } \\
\text { e o caso do Celobar }\end{array}$ & $\begin{array}{l}\text { Desenvolvimento de atitudes e } \\
\text { valores para a formação de um } \\
\text { cidadão crítico }\end{array}$ \\
\hline Maio 06 & $\begin{array}{l}\text { Experimento envolvendo óxido-redução e } \\
\text { diferença de pressão }\end{array}$ & $\begin{array}{l}\text { Desenvolvimento de atitudes e } \\
\text { valores para a formação de um } \\
\text { cidadão crítico }\end{array}$ \\
\hline Maio 06 & Experimentos com alumínio & Estratégia de ensino aprendizagem \\
\hline Maio 06 & $\begin{array}{l}\text { O reagente de Benedict na análise de } \\
\text { açúcares }\end{array}$ & $\begin{array}{l}\text { Exemplificação de fatos do } \\
\text { cotidiano }\end{array}$ \\
\hline Maio 06 & $\begin{array}{l}\text { Combustão, chamas e teste de chama para } \\
\text { cátions }\end{array}$ & $\begin{array}{l}\text { Exemplificação de fatos do } \\
\text { cotidiano }\end{array}$ \\
\hline Novembro/05 & obre oxidação enzimática & $\begin{array}{l}\begin{array}{l}\text { Exemplificação de fatos } \\
\text { cotidiano }\end{array} \\
\end{array}$ \\
\hline
\end{tabular}




\begin{tabular}{|c|c|c|}
\hline Novembro/05 & $\begin{array}{l}\text { Extração de óleo essencial de uma planta } \\
\text { da caatinga }\end{array}$ & $\begin{array}{l}\text { Exemplificação de fatos do } \\
\text { cotidiano }\end{array}$ \\
\hline Maio/05 & Fatores ambientais e precipitação úmida & $\begin{array}{l}\text { Exemplificação de fatos do } \\
\text { cotidiano }\end{array}$ \\
\hline Maio/05 & Chuva ácida, equilíbrio químico e acidez & Estratégia de ensino aprendizagem \\
\hline $\begin{array}{l}\text { Novembro/ } \\
04\end{array}$ & $\begin{array}{l}\text { Extração de pigmentos do espinafre e } \\
\text { separação em coluna de açúcar comercial }\end{array}$ & Estratégia de ensino aprendizagem \\
\hline Maio / 04 & $\begin{array}{l}\text { Experimentação em sala de aula e meio } \\
\text { ambiente: determinação simples de } \\
\text { oxigênio dissolvido em água }\end{array}$ & $\begin{array}{l}\text { Desenvolvimento de atitudes e } \\
\text { valores para a formação de um } \\
\text { cidadão crítico }\end{array}$ \\
\hline Maio/ 04 & $\begin{array}{l}\text { Confirmando a esterificação de Fischer } \\
\text { por meio dos aromas }\end{array}$ & Estratégia de ensino aprendizagem \\
\hline $\begin{array}{l}\text { Novembro/ } \\
03\end{array}$ & $\begin{array}{l}\text { A importância das propriedades físicas } \\
\text { dos polímeros na reciclagem }\end{array}$ & $\begin{array}{l}\text { Desenvolvimento de atitudes e } \\
\text { valores para a formação de um } \\
\text { cidadão crítico }\end{array}$ \\
\hline $\begin{array}{l}\text { Novembro/ } \\
03\end{array}$ & $\begin{array}{l}\text { Da água turva à água clara: o papel do } \\
\text { coagulante }\end{array}$ & $\begin{array}{l}\text { Exemplificação de fatos do } \\
\text { cotidiano }\end{array}$ \\
\hline Maio/ 03 & $\begin{array}{l}\text { Explorando a química na determinação do } \\
\text { teor de álcool na gasolina }\end{array}$ & $\begin{array}{l}\text { Exemplificação de fatos do } \\
\text { cotidiano }\end{array}$ \\
\hline Maio/ 02 & $\begin{array}{l}\text { Algumas Reações do } \text { Enxofre } \\
\text { Importância Ambiental }\end{array}$ & $\begin{array}{l}\text { Desenvolvimento de atitudes e } \\
\text { valores para a formação de um } \\
\text { cidadão crítico }\end{array}$ \\
\hline Maio/ 02 & $\begin{array}{l}\text { Polímeros Superabsorventes e as Fraldas } \\
\text { Descartáveis: um Material Alternativo } \\
\text { para o Ensino de Polímeros }\end{array}$ & $\begin{array}{l}\text { Exemplificação de fatos do } \\
\text { cotidiano }\end{array}$ \\
\hline Maio/ 02 & $\begin{array}{l}\text { Saneamento ambiental por métodos } \\
\text { eletroquímicos : I - Tratamento de } \\
\text { Soluções Aquosas }\end{array}$ & $\begin{array}{l}\text { Exemplificação de fatos do } \\
\text { cotidiano }\end{array}$ \\
\hline $\begin{array}{l}\text { Novembro/ } \\
01\end{array}$ & Decomposição térmica do PVC & $\begin{array}{l}\text { Exemplificação de fatos do } \\
\text { cotidiano }\end{array}$ \\
\hline $\begin{array}{l}\text { Novembro/ } \\
01\end{array}$ & $\begin{array}{l}\text { Determinação de cálcio e ferro em leite } \\
\text { enriquecido }\end{array}$ & $\begin{array}{l}\text { Desenvolvimento de atitudes e } \\
\text { valores para a formação de um } \\
\text { cidadão crítico }\end{array}$ \\
\hline Maio/ 01 & Plásticos: molde você mesmo! & $\begin{array}{l}\text { Exemplificação de fatos do } \\
\text { cotidiano }\end{array}$ \\
\hline Maio/ 00 & $\begin{array}{l}\text { Pilhas de } \mathrm{Cu} / \mathrm{MG} \text { construídas com } \\
\text { materiais de fácil obtenção }\end{array}$ & Estratégia de ensino aprendizagem \\
\hline
\end{tabular}




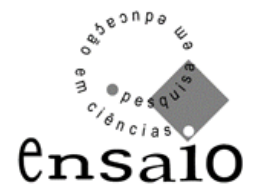

Dentre os 30 artigos analisados que contemplam contextualização, verificou-se que das três concepções de contextualização consideradas neste estudo, predominou a concepção de Contextualização como exemplificação de fatos do cotidiano, sendo verificada em $50 \%$ dos artigos (15 artigos).

Como exemplo desse tipo de contextualização, apresentamos um trecho do artigo "Estudo da Atividade Proteolítica de Enzimas Presentes em Frutos”:

\begin{abstract}
As enzimas proteolíticas são encontradas tanto em animais como em vegetais. Em animais, elas participam de importantes processos biológicos, entre os quais: a digestão protéica, a coagulação sanguínea, a morte celular e a diferenciação de tecidos. Sua atuação no processo digestivo, por exemplo, é essencial para o processo de absorção, pois hidrolisam as proteínas provenientes da alimentação para que seus aminoácidos (monômeros) possam ser absorvidos e reaproveitados pelo organismo (QNEsc $n^{\circ} 28$, maio 2008, p.47).
\end{abstract}

Este é um exemplo clássico de contextualização como exemplificação de fatos do cotidiano, porque apenas cita alguma situação ou fato do cotidiano que envolve algum conceito científico que está sendo trabalhado nas aulas, sem que seja ampliada a discussão para os aspectos sócio/econômico/culturais envolvidos.

Neste caso, para que, fosse contemplada a perspectiva de contextualização como desenvolvimento de atitudes e valores para a formação do cidadão crítico, seria interessante trazer, por exemplo, uma discussão sobre alguma patologia relacionada àqueles conceitos, como as disfunções alimentares (bulimia e anorexia), que podem afetar diretamente a absorção e fixação de nutrientes e vitaminas no organismo. Tal discussão poderia facilitar a compreensão, por parte dos jovens, de um fenômeno que tem estado bastante presente na mídia, alertando-os sobre os problemas da busca do corpo perfeito. De modo simplificado, é possível argumentar que esta é, ou deveriam ser, a função do ensino de ciências da Educação Básica defendida pelos PCN. Conforme Santos e Schnetzler (1996), os conceitos científicos deveriam ser trabalhados em sala de aula de modo a permitirem uma melhor compreensão da realidade da qual o indivíduo faz parte, e não um ensino de ciências que tenha um fim em si mesmo, ou seja, tenha como objetivo apenas a memorização de conteúdos que serão devolvidos durante as avaliações.

Outra possibilidade seria tentar uma contextualização como estratégia de ensino aprendizagem. Nesse tipo de contextualização identifica-se o emprego de situações do 


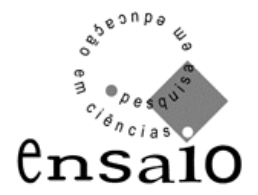

cotidiano para melhorar a compreensão de conceitos químicos por parte dos alunos. É o caso do trecho abaixo:

\begin{abstract}
Em uma visita ao supermercado, percebe-se a oferta de vários produtos para a limpeza doméstica. Essa diversidade decorre da combinação de vários componentes, tais como bases, ácidos, agentes oxidantes, tenso ativos e solventes. No entanto, assim como um produto age sobre a sujeira, este também pode deteriorar a superfície metálica de uma geladeira ou fogão. Apesar de amplamente utilizados no dia-a-dia, metais e ligas metálicas requerem cuidados específicos, pois sua conservação inadequada favorece a corrosão. (QNEsc, $\mathrm{n}^{\circ}$ 26, nov. 2007, p.44)
\end{abstract}

Neste trecho, nota-se que a abordagem do assunto é muito bem correlacionada, pois utiliza materiais do cotidiano, como detergente, e faz com que o aluno reflita quimicamente sobre sua composição, além da observação de fenômenos químicos como a corrosão. Todavia, não discute aspectos econômicos, por exemplo, que permitiriam uma reflexão mais ampliada, aquela esperada na concepção de contextualização para formação do cidadão crítico. Esta discussão seria apropriada, pois além deste, existem outros tantos exemplos de reações de óxido-redução que ocorrem freqüentemente nos mais diversos setores da sociedade, provocando consideráveis prejuízos econômicos e até acidentes que envolvem perda de vidas humanas (GENTIL, 1996).

Devido a relevância do tema, é importante que os conceitos químicos relacionados a reações de óxido-redução sejam abordados de forma mais próxima da vida dos alunos, facilitando o desenvolvimento não só da aprendizagem dos conceitos, mas de habilidades básicas para uma melhor atuação na sociedade, como destacado por Santos e Schnetzler:

\footnotetext{
Os temas químicos sociais desempenham papel fundamental no ensino de Química para formar o cidadão, pois propiciam a contextualização do conhecimento químico com o cotidiano do aluno, conclusão essa enfatizada pelos educadores como sendo essencial para o ensino em estudo. Além disso, os temas químicos permitem o desenvolvimento das habilidades básicas relativas à cidadania (...), pois trazem para a sala de aula discussões de aspectos sociais relevantes. (SANTOS \& SCHNETZLER 1996, p.30)
}

Aliada a contextualização, a experimentação é outra prática importante, pois motiva e ajuda os estudantes a compreender e elaborar tanto os pensamentos quanto os conhecimentos científicos, principalmente devido ao seu caráter investigativo. Quando bem conduzida e estruturada em bases epistemológicas claras, a experimentação surge como exercício imprescindível na atividade docente em Química. 


\section{$e^{p^{2 n p_{\theta}}} \varepsilon$ \\ $\stackrel{\infty}{3}$ \\ ensaio}

Os outros 50\% dos artigos analisados, dividiram-se nas duas outras concepções de contextualização consideradas neste estudo, quais sejam: contextualização como estratégia de ensino aprendizagem, que foi verificada em $23,3 \%$ dos artigos (7 artigos) e a contextualização como desenvolvimento de atitudes e valores para a formação do cidadão crítico, verificada em 26,7\% (8 artigos). Essas duas concepções de contextualização combinadas seriam ideais para o ensino de química que vem sendo defendido (SANTOS \& SCHNETZLER, 1996; CHASSOT et al., 1993; GIORDAN, 1999), pois possibilitariam, além da compreensão de conceitos químicos, o desenvolvimento de atitudes e valores para a formação do cidadão crítico, permitindo a atuação desse indivíduo na sociedade atual, com uma melhor compreensão da mesma.

No trecho a seguir, é possível verificar um exemplo de concepção de contextualização como desenvolvimento de atitudes e valores para a formação do cidadão crítico:

No decorrer do ano de 2003, um fato envolvendo a morte de pelo menos 23 pessoas e a intoxicação de dezenas de outras em vários Estados brasileiros chamou a atenção da mídia e da opinião pública brasileira. Investigações realizadas na época pela Agência Nacional de Vigilância Sanitária indicaram que o produto Celobar ${ }^{\circledR}$ - um contraste radiológico largamente utilizado em exames de enema opaco, radiografia de esôfago, estômago, intestinos e dos vasos da base do coração - teve a composição adulterada durante sua fabricação. Sais como o sulfato de bário e o carbonato de bário são pouco solúveis em meio aquoso de $\mathrm{pH}$ neutro: aproximadamente $2,45 \mathrm{mg} \mathrm{L}^{-1}(1,05 \times$ $\left.10^{-5} \mathrm{~mol} \mathrm{~L}^{-1}\right)$ e $17,8 \mathrm{mg} \mathrm{L}^{-1}\left(9,00 \times 10^{-5} \mathrm{~mol} \mathrm{~L}^{-1}\right)$, a $25^{\circ} \mathrm{C}$, respectivamente. $\mathrm{O}$ Celobar ${ }^{\circledR}$ é uma suspensão aquosa de sulfato de bário de concentração 1 g.mL $\mathrm{mL}^{-1}$ e a dosagem recomendada para adultos é de $30 \mathrm{~mL}$. Considerando as baixas solubilidades citadas, em condições normais essa dosagem não seria suficiente para atingir a dose mínima letal de 2 a $3 \mathrm{mg}$ de bário por quilo de tecido. Por que, então, a contaminação do Celobar ${ }^{\circledR}$ com o carbonato de bário provocou a morte de um número significativo de pessoas? (QNEsc, n 24, nov. 2006, p.43)

Entendemos que o artigo representado pelo trecho acima, possibilita o enfrentamento de uma das grandes preocupações do Ensino de Ciências retratada nos documentos oficiais (BRASIL, 2002), que é a busca por um ensino de ciências que garanta a união entre os fatos e fenômenos vivenciados no dia-a-dia, suas respectivas implicações sócio-econômico-culturais, juntamente com os conhecimentos teóricocientíficos neles implícitos. Consideramos que trabalhar a contextualização a partir desta concepção, contribui para a formação de um cidadão mais consciente, visto que esse tipo 


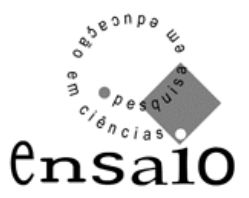

de abordagem dos conteúdos instiga o aluno ao aprendizado, uma vez que traz um fato real, que teve certa repercussão social, além de envolver conceitos químicos de forma contínua ao longo da contextualização.

Conforme foi apresentado, observou-se que das três concepções de contextualização consideradas, a que prevaleceu foi a contextualização como exemplificação de fatos do cotidiano (50\%), seguida da contextualização como desenvolvimento de atitudes e valores para a formação do cidadão crítico $(26,7)$ e da contextualização como estratégia de ensino aprendizagem (23,2\%).

Apesar de vários trabalhos estarem, ao longo dos últimos anos, sendo desenvolvidos com base na contextualização, nota-se que ainda há predominância de uma concepção de contextualização considerada restrita, a qual se resume à exemplificação de fatos do cotidiano. Esta concepção, conforme Mortimer e Santos (1999) apenas relaciona o ensino de ciências ao cotidiano, sem haver inter-relações entre esses conteúdos e aspectos sócio-econômicos-culturais, ou seja, a abordagem continua centrada nos conteúdos científicos apenas.

Salientamos, no entanto, que a predominância desta concepção de contextualização, não se restringe apenas aos artigos da Revista que está sendo pesquisada, mas é encontrada principalmente nos livros didáticos de química conforme pesquisa realizada por Wartha e Alário, na qual, apontam que em nenhum dos livros por eles analisados foi verificada a concepção de contextualização "na perspectiva da discussão de temas sociais, ambientais, tecnológicos, éticos, econômicos sob o olhar da Química de modo a fornecer informações ao estudante enquanto cidadão” (WARTHA \& ALÁRIO, 2005, p.46).

Conforme foi discutido no início, reafirmamos que essa visão limitada da função do ensino de química, tem uma relação direta com a formação inicial dos professores, a qual historicamente tem valorizado a formação do bacharel em detrimento da formação do licenciado (MALDANER, 2002). Tal formação acaba apresentando como resultado, profissionais que atuam na área de ensino de Ciências/Química que, não tiveram a oportunidade de refletir sobre questões fundamentais da área de Ensino de Ciências e, portanto, acabam repetindo uma postura tradicional de ensino, na qual não está presente, 


\title{
$0^{p^{20 n p_{\theta}}} \varepsilon$ \\ $\stackrel{\infty}{3} \oplus_{0}$ \\ ensaio
}

por exemplo, a preocupação com um ensino de ciências/química voltado para a formação do cidadão.

No Critério 3, foi analisado se a contextualização empregada nos experimentos era coerente com os conceitos químicos envolvidos. Verificou-se que em 83\% dos artigos há tal coerência e, em 17\% , esta não foi verificada. Um exemplo no qual essa coerência é encontrada está no trecho abaixo:

\begin{abstract}
Segundo dados da Organização das Nações Unidas (ONU), cerca de um milhão de crianças morrem devido à desidratação causada pela diarréia. [...] Desde 1980, a Unicef, em sua campanha para salvar vidas de crianças, distribui em mais de 60 países envelopes contendo uma mistura de sais para reidratação oral. Esse envelope possui uma constituição química conhecida: cloreto de sódio (2,6 g L-1), glicose (13,5 g L-1), cloreto de potássio (1,5 g L-1) e citrato de sódio (2,9 g L-1). [...] No entanto, por que essa mistura de substâncias tão comuns é capaz de salvar vidas de crianças em alto grau de desidratação? $\mathrm{O}$ processo envolvido nessa questão é o que chamamos de osmose, que é a passagem de um solvente através de uma membrana semipermeável que separa duas soluções de diferentes concentrações. (QNEsc, n² 26, nov. 2007).
\end{abstract}

Este trecho, além de apresentar um exemplo de contextualização coerente com os conceitos químicos envolvidos no experimento, abrange também duas das concepções de contextualização descritas nesta pesquisa “contextualização como estratégia de ensino aprendizagem” e “contextualização como desenvolvimento de atitudes e valores para a formação de um cidadão crítico”. Conforme já foi demonstrado, essa abrangência é muito rara, pois normalmente a concepção mais recorrente é a de contextualização como exemplificação de fatos do cotidiano e dificilmente existe conexão entre a tentativa de contextualização e os conceitos químicos envolvidos no experimento.

Quanto ao Critério 4, no qual buscou-se verificar quais foram os conteúdos contextualizados mais recorrentes, observou-se que tais conteúdos foram os relacionados a alimentos (8 artigos), meio ambiente (7 artigos), e plásticos (4 artigos). Além disso, consideramos que os artigos apresentaram possibilidade de trabalho interdisciplinar, mais freqüentemente entre as área de Química e Biologia, como por exemplo: atividades enzimáticas, reações no corpo humano, vegetais e seus princípios ativos, entre outros.

No Critério 5, tivemos como objetivo analisar se ao longo das edições de 2000 a 2008 houve um aumento na proposição de artigos com experimentos contextualizados. Observou-se que os primeiros artigos analisados (a partir do ano 2000) traziam em sua 


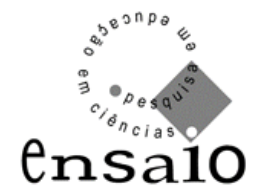

maioria uma concepção de contextualização limitada, ou seja, uma concepção de contextualização como exemplificação de fatos do cotidiano. Em contrapartida, nas edições mais recentes (a partir de 2006) os experimentos apresentaram, mais freqüentemente, tentativas de contextualização mais abrangentes. Ou seja, desse período em diante, foi verificada a presença de artigos que contemplavam a concepção de contextualização como desenvolvimento de atitudes e valores para a formação do cidadão crítico, o que, conforme vimos defendendo, pode promover um maior desenvolvimento do conhecimento não somente conceitual, no que diz respeito aos conteúdos de química envolvidos no experimento, mas também um desenvolvimento da compreensão de aspectos sócio-econômico-culturais por parte dos alunos.

\section{CONSIDERAÇÕES FINAIS}

Com esta pesquisa, verificou-se que a maioria dos artigos analisados $(68 \%=30$ dos 44 artigos analisados) dos últimos oito anos da revista Química Nova na Escola, apresentou tentativas de contextualização do ensino de química. Todavia, observou-se que a concepção de contextualização presente em 50\% destes (15 artigos), é aquela considerada "limitada", a qual apenas cita fatos do dia-a-dia, ou seja, corresponde à contextualização como exemplificação de fatos do cotidiano.

Já a contextualização que prevê o desenvolvimento de atitudes e valores para a formação do cidadão crítico, que seria a desejável, por possibilitar a atuação desse cidadão na sociedade atual, com uma melhor compreensão desta, foi encontrada mais frequentemente a partir do ano de 2006, estando em apenas 26,7\% dos artigos que apresentaram algum tipo de contextualização. Todavia, essa freqüência mais recente, nos permite considerar que, apesar de haver predominado a concepção de contextualização como exemplificação de fatos do cotidiano, dentre os artigos que apresentaram algum tipo de contextualização, está começando a ocorrer uma melhor compreensão da concepção de contextualização desejável, ou seja, aquela que vem sendo proposta pelos documentos oficiais e pela literatura da área. Fazemos essa afirmação com base na observação de que, não apenas houve um aumento do número de artigos com propostas de experimentos 


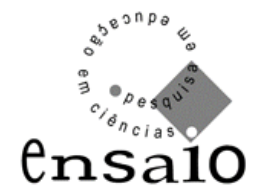

contextualizados, mas também que a concepção de contextualização está, aos poucos, se aproximando da concepção de contextualização como desenvolvimento de atitudes $e$ valores para a formação do cidadão crítico.

A interpretação que fazemos desse dado é que começa a haver, também lentamente, uma mudança na estrutura dos cursos de graduação em química. Ou seja, a área de Ensino de Química começa a ser valorizada dentro desses cursos, com a contratação de professores/doutores com formação nessa área, o que aos poucos, vem começando a repercutir na formação dos docentes atuantes na área e, conseqüentemente, na sua visão de ensino de ciências e nos artigos por eles publicados.

Em relação à coerência entre a contextualização e os conceitos químicos abordados, verificou-se que em 83\% dos casos, ocorreu essa coerência. Este é um dado que consideramos bastante positivo, se fizermos uma comparação com alguns livros didáticos de química, por exemplo. Em alguns destes é comum encontrarmos "tentativas de contextualização", feitas geralmente em quadros separados do texto e sem relação com o conteúdo que está sendo tratado. Esse tipo de livro infelizmente ainda é bastante comum, são editados a partir de uma visão de ensino de ciências tradicional, porém com uma "maquiagem de contextualização".

No que se refere aos conteúdos que foram mais recorrentes, observou-se que certos temas são mais explorados que outros, nos artigos que apresentam algum tipo de contextualização. Dentre eles destacaram-se conteúdos relacionados a alimentos, meio ambiente e plásticos. Consideramos o destaque desses temas também bastante positivo, uma vez que demonstra uma preocupação, por parte dos autores dos artigos, no sentido de contemplar assuntos que têm estado mais presentes na sociedade atual, contribuindo, portanto, para a formação do "cidadão crítico", postura que foi defendida ao longo deste estudo.

Concluímos argumentando que o fato de uma revista como a Química Nova na Escola, a qual é direcionada a professores de química e alunos do da Educação Básica, contemplar artigos que apresentam experimentos contextualizados, pode contribuir para o processo ensino-aprendizagem, uma vez que a partir desta abordagem, o experimento deixa de ter como objetivos apenas a "comprovação da teoria" e o "papel motivador" e 


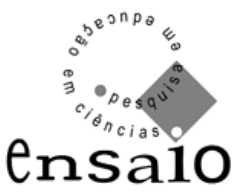

passa a ser uma metodologia que pode contribuir para a formação do cidadão critico, objetivo fundamental a ser buscado, na perspectiva de um ensino de química que rompa com o modelo tradicional, que há tanto tempo vem sendo criticado.

Salientamos que a contextualização não é um critério desta Revista para publicação na seção “Experimentação no Ensino de Química”. Esta foi uma problemática levantada especificamente para este estudo. No entanto, pode-se observar que a Revista apresentou um enriquecimento, não apenas no que diz respeito ao número de experimentos que propõem contextualização, como também na concepção de contextualização que vêm sendo proposta, ao longo das edições.

\section{REFERÊNCIAS BIBLIOGRÁFICAS}

ABREU, R. G.; GOMES, M. M.; LOPES, A. C. Contextualização e Tecnologias em Livros Didáticos de Biologia e Química. Investigações em Ensino de Ciências, v.10, n.3, 2006.

BRASIL. Ministério da Educação. MEC, Secretaria de Educação Média e Tecnológica Semtec. Parâmetros Curriculares Nacionais para o Ensino Médio. Brasília: MEC/Semtec, 1999a.

BRASIL. Secretaria de Educação Média e Tecnológica. PCN + Ensino Médio: Orientações educacionais complementares Parâmetros Curriculares Nacionais para o Ensino Médio. Ciências da Natureza, Matemática e suas tecnologias. Brasília: MEC, SEMTEC, 2002.

CHASSOT, A. I. et al. Química do Cotidiano: pressupostos teóricos para a elaboração de material didático alternativo. Espaços da Escola, n.10, p.47-53, 1993.

GALIAZZI, M. C. et al. Objetivos das Atividades Experimentais no Ensino Médio: A pesquisa coletiva como modo de formação de professores de ciências. Ciência \& Educação, v.7, n.2, 2001.

GALIAZZI, M. C.; GONCALVES, F. P.; A natureza pedagógica da experimentação: uma pesquisa na licenciatura em química. Química Nova, 2004, n.27, 326-331.

GENTIL, V.; Corrosão. 4. ed., Rio de Janeiro: LTC, 1995. 


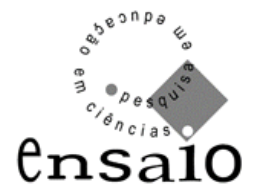

GIORDAN, M.; O papel da experimentação no Ensino de Ciências. Química Nova na Escola, n.10, 1999.

GOUVEA, L. R.; MACHADO, A. H.; Trilhando Caminhos para Compreender a Contextualização no ensino de Química. 2005. Monografia (conclusão de curso) Graduação em Química Licenciatura, Faculdade de Educação, Universidade Federal de Minas Gerais, Belo Horizonte.

LIMA, S. L. et al. Aspectos Didáticos e Implicações do Uso de Aulas Demonstrativas de Química. Trabalho apresentado ANNQ. Disponível em $<$ www.annq.org/congresso2007>. Acesso em 25/06/08.

LISO, M. R. J.; GUADIX, M. A.; TORRES, E. M.; Química Cotidiana para la Alfabetización Científica: ¿realidad o utopia? Educación Química, v.13, n.4, p.259-266, 2002.

LOPES, A. C. Os Parâmetros Curriculares Nacionais para o Ensino Médio e a Submissão ao Mundo Produtivo: O caso do conceito de contextualização. Educação \& Sociedade, v.23, n.80, set. 2002.

LOPES, A. R. C. Conhecimento escolar: ciência e cotidiano. Rio de Janeiro: Editora da UERJ, 1998.

MALDANER, O. A. A pesquisa como perspectiva de formação continuada do professor de química. Química Nova, v.22, n.2, 1999.

A formação inicial e continuada de professores de química: professores/pesquisadores. Ijuí: UNIJUí, 2000.

MORTIMER, E. F.; SANTOS, W. P. A dimensão social do ensino de química: um estudo exploratório da visão de professores. In: II Encontro Brasileiro de Pesquisa em Ensino de Ciências, 1999, Valinhos. Anais II Encontro Brasileiro de Pesquisa em Ensino de Ciências. Florianópolis: ABRAPEC, 1999. p.1-9.

RICARDO, H. Competências, Interdisciplinaridade e Contextualização: dos Parâmetros Curriculares Nacionais a uma compreensão para o ensino das ciências. Tese (Doutorado em Educação Cientifica e Tecnológica) - Universidade Federal de Santa Catarina, 2005.

SANTOS, W. L. P.; SCHNETZLER, R. P. Função Social: o que significa ensino de química para formar cidadão? Química Nova na Escola, n.4, nov. 1996. 


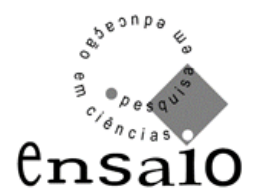

WARTHA, E. J.; ALARIO, A. F. A Contextualização no Ensino de Química Através do Livro Didático. Revista Química Nova na Escola, n.22, 2005.

Data de recebimento: 27/01/09

Data de aprovação: 26/06/09

Data de versão final: 31/07/09 